\title{
www.czasopisma.pan.pl \\ Effects of South African Silica Sand Properties on the Strength Development and Collapsibility of Single Component Sodium Silicate Binders
}

\author{
F.C Banganayi ${ }^{a, *}$, K Nyembwe ${ }^{b}$, H Polzin ${ }^{c}$ \\ ${ }^{a}$ Metal Casting Technology Station, University of Johannesburg, 37 Nind street Doornfontein, Johannesburg, South Africa \\ ${ }^{\mathrm{b}}$ Department of Metallurgy, University of Johannesburg, 37 Nind street Doornfontein, Johannesburg, South Africa \\ ${ }^{c}$ Technische Universität Bergakademie Freiberg/Gießerei-Institut Bernhard -von-Cotta-Strasse 4 Freiberg Germany \\ *Corresponding author. E-mail address: fcbanganayi@uj.ac.za
}

Received 19.10.2016; accepted in revised form 12.07.2017

\begin{abstract}
This study shows the results of the investigation of the strength performance, and residual strength of a single component inorganic binder system Cast Clean S27®. The study was conducted using three different foundry sand sources in South Africa. Sample A is an alluvial coastal sample, sample B is an alluvial riverbed sample and Sample C is a blasted sample from a consolidated quartzite rock. The binder was also cured using three different curing mechanisms. The aim of the investigation was to determine the variation of strength performance and residual strength between the different South African sand sources based upon the physical and chemical properties of the sand sources. The moulding sand was prepared using three possible curing mechanisms which are carbon dioxide curing, ester curing and heat curing. The strength measurements were determined by bending strength. Sample A and sample C sand had good strength development. Sample B sand had inferior strength development and excellent high temperature residual strength. The study showed that the single component inorganic binders have good strength development and low residual strength. The silica sand properties have major contributing factors on both strength development and residual strength. The degree of influence of silica sand properties on strength performance and residual strength is dependent on the time of curing and method of curing.
\end{abstract}

Keywords: Inorganic binders, Strength development, Collapsibility

\section{Introduction}

The growing demands of ecology and economy promote continuous interest in the non-toxic and cheap, inorganic binders compared to organic binders [1]. In the sand casting process, sodium silicate bonded sand is considered to be the most favourable green and pollutant free moulding sand, essentially with no toxic gas emission [2] Despite the numerous advantages inorganic binders' indisputable drawback is too high residual strength and hence poor knocking out properties [3] Modifiers, improve the sand collapsibility after hardening. The knocking out properties and reclaimability of the used sand mixture can also be improved with an addition of organic and inorganic modifiers [3]. In the selection of base material it is essential to select the sand based on a number of factors. The quality of the sand based on the 
type, size and process adopted for the manufacture of the castings [4]. Most sand moulds and cores are based on silica sand since it is the most readily available and lowest cost moulding material. Other sands are used for special applications where higher refractoriness, higher thermal conductivity or lower thermal expansion is required [5.] Practical experience and moulding data show that $40-70 \%$ of the casting defects arise from inadequate mould properties [6] There are generally three hardening methods of the sodium silicate moulds including heat curing, carbon dioxide gas curing, and ester curing.

The working principle of the $\mathrm{CO}_{2}$ process is based on the fact that if $\mathrm{CO}_{2}$ gas is passed through a sand mixture containing sodium silicate as the binder, immediate hardening of sand takes place as a result of the chemical reaction between sodium silicate and carbon dioxide [7] Self-curing water glass mixtures with liquid hardeners form the class of esters such as diacetin, triacetin, ethylene glycol diacetate. The solidification reaction proceeds by the formation of an acid to the formation of a salt sodium acetate. The solidification of the mould occurs in a series of hydrolysis reactions [8]. The heat curing may be affected by different mechanisms such as drying in still air, cold or hot air, gas flow and drying in hot or warm tools. For all these processes the principle of hardening by dehydration is the same, but the conditions for the transfer of moisture from the system and hence the curing speed are different [8.]

Despite the knowledge accumulated with regards to sodium silicate moulding technology, it is not always possible to predict how a new commercial binder will perform with untested refractory sands. This paper tackles this questions in the case of a new generation single component inorganic binder. Most new generation inorganic binders come in two components Part 1 (the binder) Part 2 (breakdown or flowability agent). Cast Clean S27 $(\mathbb{B}$ is an inorganic binder with an inorganic breakdown and floawibilty agent already incooperated into the binder making it a single component binder. The used binder has a density of 1.45 $\mathrm{g} / \mathrm{cm}^{3}$ and a modulus ratio between $\mathrm{SiO}_{2}$ and $\mathrm{Na}_{2} \mathrm{O}$ of 2.45 .

\section{Sand characterisation and moulding sands preparation}

Three different South African silica sands supplied to the foundry market were selected based upon geological origin. Sample A is a Western Cape silica sand coastal alluvial sand. Sample B is a Vaal silica sand from alluvial from the Vaal riverbed. Sample C is a Delmas silica sand blasted quartzite rock. The selected sands were evaluated based upon the experimental design in figure 1.

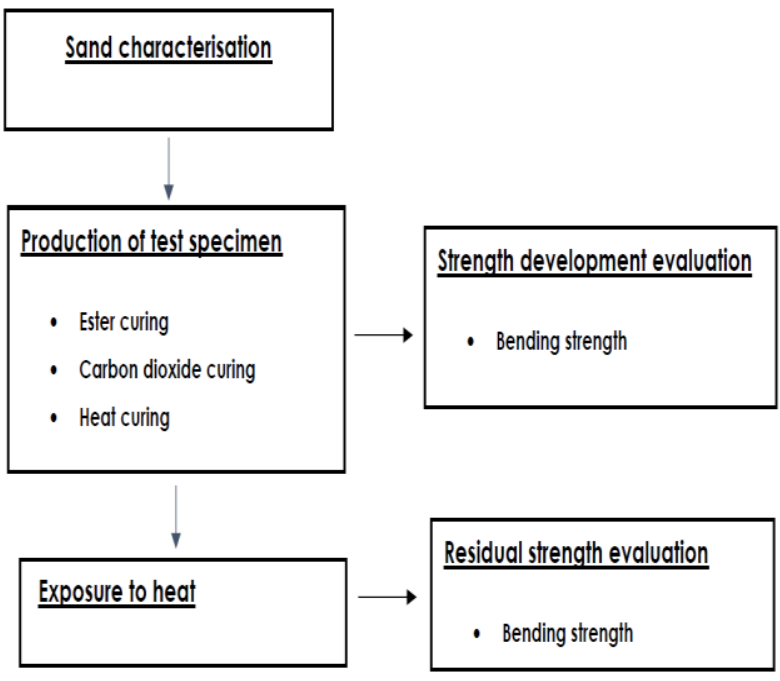

Fig. 1. Experimental design

The sand was characterized for the following properties,

- chemical analysis,

- $\quad$ average grain size,

- $\quad$ particles size distribution,

- $\quad$ specific surface area,

- coefficient of angularity

- clay content,

- $\mathrm{pH}$

Bend test specimen for strength development evaluation were prepared using the standard addition by mixing with $3 \%$ per weight of the sand of sodium silicate binder and under the conditions given in table 1 .

Table 1.

Moulding sand preparation parameters for strength development evaluation

\begin{tabular}{|c|c|c|c|}
\hline \multicolumn{4}{|c|}{ Curing for strength development evaluation } \\
\hline Curing method & $\begin{array}{l}\text { Carbon } \\
\text { dioxide }\end{array}$ & Ester & Heat \\
\hline Parameters & $\begin{array}{l}5 \text { liters } \\
\text { /minute }\end{array}$ & $\begin{array}{l}10 \% \\
\text { hardener }\end{array}$ & $\begin{array}{l}3.3 \mathrm{KW} \\
250^{\circ} \mathrm{C}\end{array}$ \\
\hline Time & $5-60$ seconds & $\begin{array}{l}1,2,3,4,5 \\
\text { and } 24 \\
\text { hours }\end{array}$ & $\begin{array}{l}60-300 \\
\text { seconds }\end{array}$ \\
\hline
\end{tabular}

Bend test specimen for residual strength evaluation were prepared using the standard addition by mixing with $3 \%$ per weight of the sand of sodium silicate binder and under the conditions given in table 2 . 
Table 2.

Moulding sand preparation for residual strength evaluation.

\begin{tabular}{llll}
\hline \multicolumn{4}{l}{ Curing for residual strength evaluation } \\
\hline Curing method & $\begin{array}{l}\text { Carbon } \\
\text { dioxide }\end{array}$ & Ester curing & Heat curing \\
\hline Parameters & $\begin{array}{l}\text { Flow rate } 5 \\
\text { litres/ } \\
\text { minute }\end{array}$ & $\begin{array}{l}10 \\
\text { hardener }\end{array}$ & $3.3 \mathrm{KW}$ \\
& 10 seconds & 24 hours & $\begin{array}{l}300 \\
\text { seconds }\end{array}$ \\
\hline Time & & &
\end{tabular}

The samples upon curing at the prescribed conditions given in table 2 were exposed to heat at temperatures ranging from $300^{\circ} \mathrm{C}$ $1200^{\circ} \mathrm{C}$. The exposure time was 5 minutes. Thereafter the samples were left to cool to room temperature and tested for bending strength.

\section{Results and discussion}

The results are presented in terms of the silica sand source characterisation, strength development evaluation and residual strength evaluation.

\subsection{Characterisation of silica sands}

Table 3 presents the results from the chemical properties of the silica sand sources obtained by X-ray Fluorescence (XRF) and the $\mathrm{pH}$. Table 4 presents the physical properties of the silica sand sources.

Table 3.

Chemical composition of silica sands

\begin{tabular}{|c|c|c|c|}
\hline Compound & $\% \mathrm{~A}$ & $\%$ B & $\% \mathrm{C}$ \\
\hline $\mathrm{SiO}_{2}$ & 95.98 & 92.02 & 96.20 \\
\hline $\mathrm{Na}_{2} \mathrm{O}$ & 0.14 & 0.16 & 0.10 \\
\hline MgO & 0.10 & 0.07 & 0.07 \\
\hline $\mathrm{Al}_{2} \mathrm{O}_{3}$ & 2.62 & 4.24 & 2.09 \\
\hline $\mathrm{P}_{2} \mathrm{O}_{5}$ & 0.02 & 0.03 & 0.02 \\
\hline $\mathrm{SO}_{3}$ & 0.19 & 0.55 & 0.33 \\
\hline $\mathrm{K}_{2} \mathrm{O}$ & 0.40 & 1.63 & 0.44 \\
\hline $\mathrm{CaO}$ & 0.11 & 0.06 & 0.24 \\
\hline $\mathrm{TiO}_{2}$ & 0.18 & 0.23 & 0.06 \\
\hline $\mathrm{Cr}_{2} \mathrm{O}_{3}$ & - & 0.05 & 0.05 \\
\hline pH & 5.84 & 6.75 & 6.39 \\
\hline
\end{tabular}

Sample A and sample C silica sands have almost similar chemical compositions. The chemical composition results in table 3 show that sample A and sample $\mathrm{C}$ are medium grade foundry silica sands. Sample B sand is a low grade foundry silica sand. Sample sand has a high alkali content, high alumina content and a low silica content in comparison to sample A and sample C, as well as other sand that can be classified as high grade foundry sands. The $\mathrm{pH}$ of all three silica sand sources is acidic as expected of silica sand.
Table 4.

General sand properties

\begin{tabular}{llll}
\hline Sand Type & Sample A & Sample B & Sample C \\
\hline AGS $\boldsymbol{\mu m}$ & 260 & 320 & 295 \\
\hline $\begin{array}{l}\text { Specific Surface } \\
\text { area }\left(\mathrm{cm}^{2} / \mathrm{g}\right)\end{array}$ & 176.00 & 142.00 & 152.00 \\
\hline $\begin{array}{l}\text { Coefficient of } \\
\text { angularity (E) }\end{array}$ & 1.78 & 1.73 & 2.19 \\
\hline Clay content (\%) & 0.45 & 1.20 & 0.30 \\
\hline
\end{tabular}

Sample A sand is a relatively fine sand as compared to sample B and sample $\mathrm{C}$ sand which are relatively coarser. The fineness also results in a high specific surface area for sample A sand. Sample A and sample B sand have almost similar coefficients of angularity, but sample $\mathrm{C}$ has a very high coefficient of angularity. Sample B has a high clay content as compared to sample C. The tested sand physical and chemical properties are most likely going be of benefit or disbenefit to the strength development of cast clean $\mathrm{S} 27 \AA$.
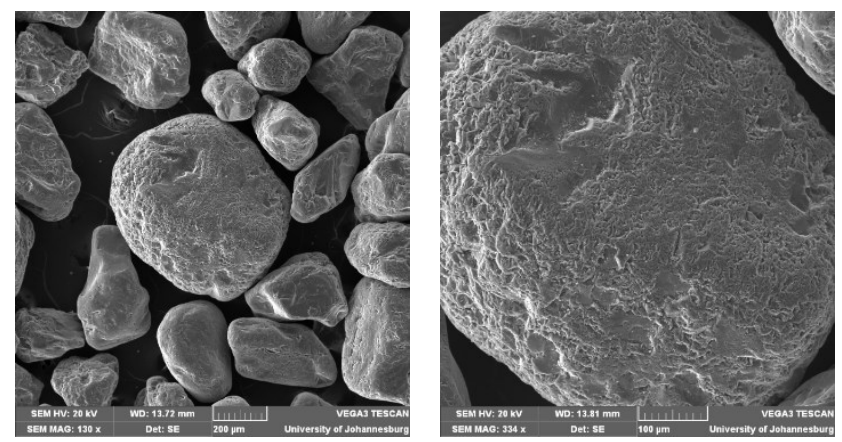

Fig. 2. Sample A silica sand left X 130 magnification and right X 334 magnification subrounded sand grains with medium sphericity
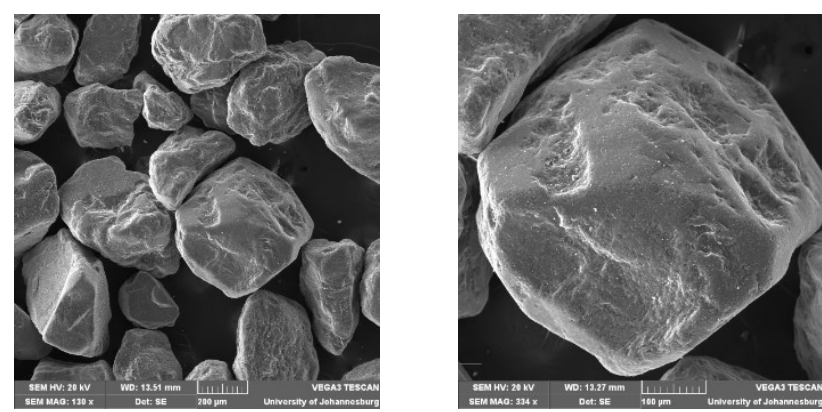

Fig. 3. Sample B silica sand left X 130 magnification and right $X$ 334 magnification subangular sand grains with medium sphericity 

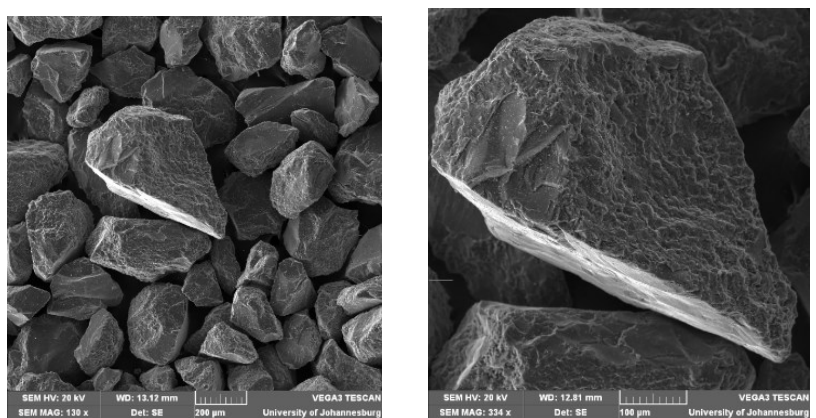

Fig. 4. Sample A silica sand left X 130 magnification and right $X$ 334 magnification angular sand grains with medium sphericity

Figure 2, Figure 3 and Figure 4 represent the different grain shapes of the chosen South African silica sands. Sample A has sub rounded and rough grains, sample B has sub angular and smooth grains and sample $\mathrm{C}$ has angular and rough grains. All three sands have medium sphericity.

\subsection{Strength development evaluation}

The strength development evaluation was performed based on the three curing mechanisms.

The strength development of Cast clean S27® using the K3 hardener is slower than that of Zakłady Chemiczne "Rudniki" using its Mach 3 hardener, but the cast clean S27 has 24 hour strengths between $155-280 \mathrm{~N} / \mathrm{cm}^{2}$. This is mainly dependent on the refractory sand properties. The 24 hour strength of Zakłady Chemiczne "Rudniki" using its Mach 3 hardener was $207 \mathrm{~N} / \mathrm{cm}^{2}$ at $3.5 \%$ binder and $0.4 \%$ hardener [12]. Figure 5 and Figure 6 show that Cast clean $\mathrm{S} 27 \AA$ is an equally competitive inorganic binder regardless of the fact that a less amount of hardener was used $3 \%$ compared to $3.5 \%$.

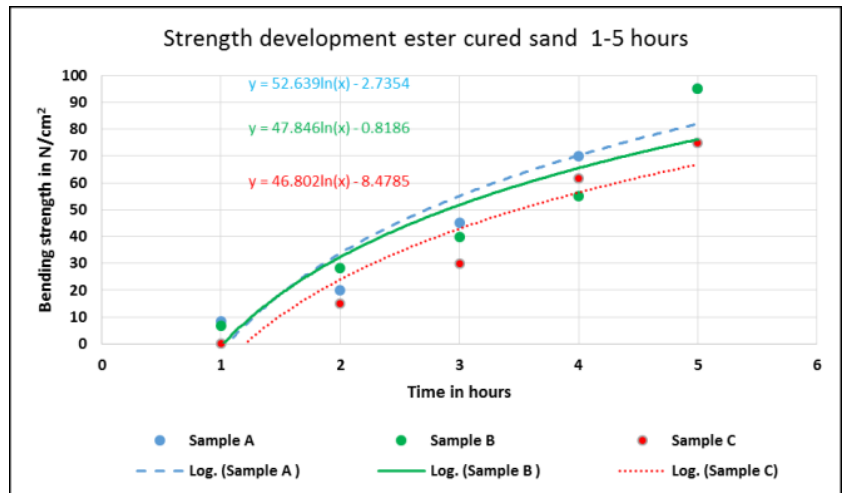

Fig. 5. Strength development with ester cured binder 1-5 hours

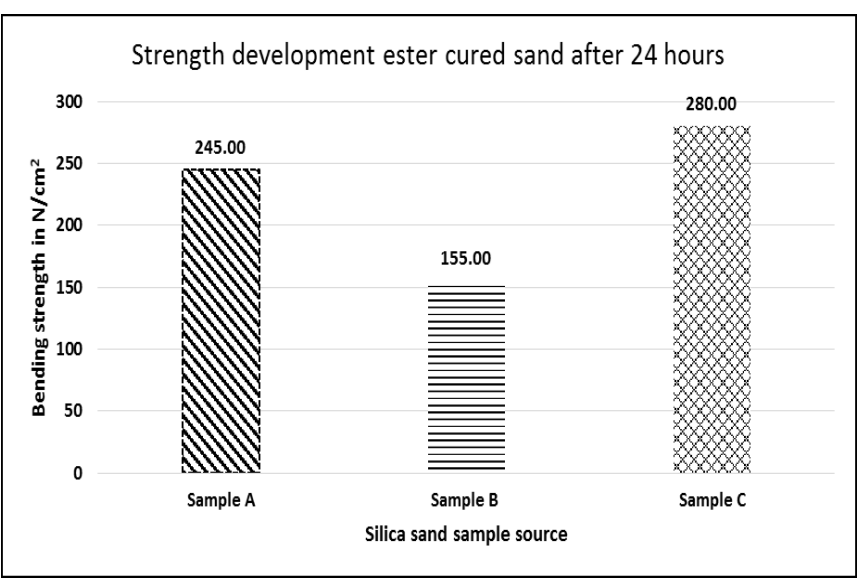

Fig. 6. Strength development with ester cured binder 24 hours

Sample A and sample B sand show almost similar trends in terms of strength development with ester cured sand between 1-2 hours as illustrated in figure 5. Sample A and sample B sands have higher strength developments relative to sample $\mathrm{C}$. The strength in sample $\mathrm{C}$ is lower due to the higher coefficient of angularity presented in table 3 that does not allow for the interaction of several bonds between the silica sand grains. The difference in strength between Sample A and sample B widened from 3-5 hours with sample A exhibiting much higher strength. In figure 6 sample B shows the lowest strength after 24hours. The most probable causes of the lower strengths is a high alkali oxides mainly $\mathrm{K}_{2} \mathrm{O}$ which is much higher relative to sample $\mathrm{A}$ and sample $\mathrm{C}$ and high clay content. The high amount of alkali oxides increases the amount of hardener or catalyst required in order to attain a given strength [9]. The clay content increases the chances of adhesion failure associated with weak bonding [10]. The trend line in figure 5 when compared to results in table 3 and 4 indicates that the influence of angularity in diminishing strength properties is not as profound as that of clay content after 24 hours as shown in figure 6 , but has a significant effect between 1-5 hours. Sample A is a sub rounded sand and sample $\mathrm{C}$ is an angular sand as illustrated by figure 2 and figure 4 respectively. The results are also confirmed by the coefficient of angularity $(\mathrm{E})$ in table 3 sample A is 1.78 and sample $\mathrm{C}$ is 2.19 the greater the number the more angular the sand grains. The strength results on the bar chart in figure 6 after 24 hours indicate that regardless of the angularity sample $\mathrm{A}$ and sample $\mathrm{C}$ had almost similar strength properties with ester cured systems. Sample C had a higher strength indicating that clay content as presented in table 4 is more likely to have a greater influence in diminishing strength with increased curing time.

The line graph in Figure 5 is represented by equations (1), (2) and (3).

\section{Sample A ester cured}

$\mathrm{y}=52,639 \ln (\mathrm{x})-2.7354$

Sample B ester cured

$y=46.802 \ln (x)-8.4785$ 
Sample C ester cured

$\mathrm{y}=47.846 \ln (\mathrm{x})-0.8186$

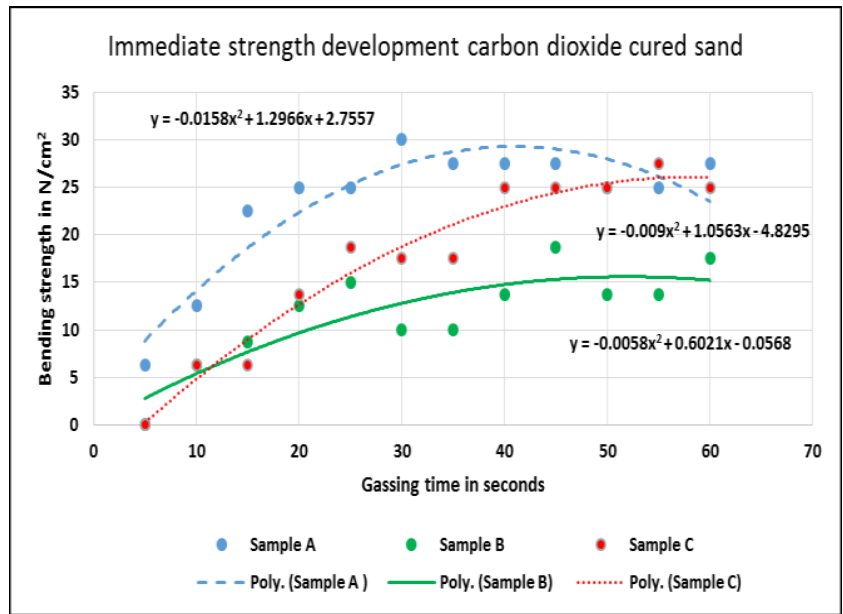

Fig. 7. Immediate strength development with carbon dioxide cured binder

The immediate strength of carbon dioxide cured sands was evaluated against gassing time. Sample A sand showed the best performance with carbon dioxide curing. Sample A sand can achieve high strengths with minimum gassing. Sample $\mathrm{C}$ sand can achieve high strengths but requires almost double the gassing time required by sample A to achieve a similar strength. The sand from sample B has low strengths even with increased gassing. The results obtained on the bending strength trend line indicate that the influence of clay content on diminishing strength is much more dependent on the gassing time surpassed so that the angularity can have better strengths. Sample A has a sub rounded grain shape and less clay $(0.45 \%)$ allowing for easy flow of carbon dioxide gas. Sample $\mathrm{C}$ has much more less clay $(0.30 \%)$ but however has greater angularity (E) (2.19) that impedes the easy flow of carbon dioxide gas therefore it takes it much more time and carbon dioxide gas to achieve higher strength. Sample B though sub rounded the clay content is too high $(1.20 \%)$ to allow for easy flow of gas [10]. The results for carbon dioxide performance at a similar module binder of 2.5 compared to the study by Stachowicz using a binder from Zakłady Chemiczne "Rudniki" are almost similar with gassing time for 60 seconds. The strength is about $20 / \mathrm{Ncm}^{2}$ with sands that have low clay content, however with higher clay content sand it's about $15 / \mathrm{Ncm}^{2}$ as presented in figure 7 . The interesting point is that with gassing time less than 60 seconds with sands that have a less clay content better strengths can be achieved. The better strengths can be achieved from 15-40 seconds and are mainly dependent on the grain shape with more rounded sand grains achieving higher strengths at a faster rate.

The line graph in Figure 7 is represented by equations (4), (5) and (6).

Sample A carbon dioxide cured

$y=-0.01580 x^{2}+1.2966 x+2.7557$
Sample B carbon dioxide cured

$y=-0.0058 x^{2}+0.6021 x-0.0568$

Sample C carbon dioxide cured

$y=-0.009 x^{2}+1.0563 x-4.8295$

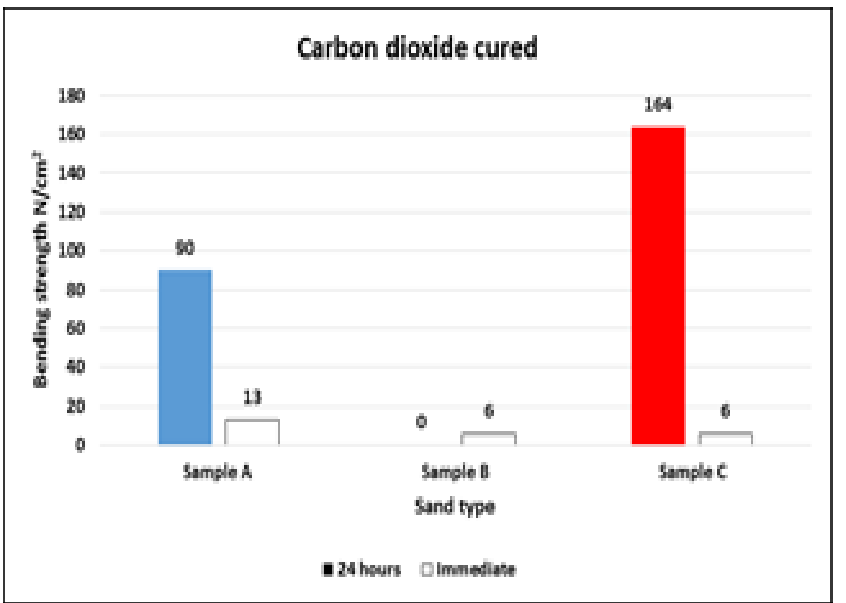

Fig. 8. Strength development with 10 s gassing time carbon dioxide cured sand after 24 hours

The carbon dioxide cured strength development after 24 hours with minimal gassing time of 10 seconds is much higher for sample $\mathrm{A}$ and sample $\mathrm{C}$. The strength more than doubles the strength in figure 3 which is optimized through additional gassing time. Sample A and C managed to create siloxane linkages which are stronger bonds formed by dehydration. Sample B completely loses strength after 24 hours. The high clay content could have resulted in over gassing in areas close to the surface thus creating very weak points that could not resist moisture as well as allow formation of the siloxane linkages that could allow the entire sample to maintain rigidity. The strength of sample $\mathrm{C}$ is very much outstanding as compared to other silica sands. The reasons for this is could be the lower clay content allowing for better strength and the availability of more contact points to be allowed to cure via dehydration forming the stronger siloxane linkage $[10]$. 


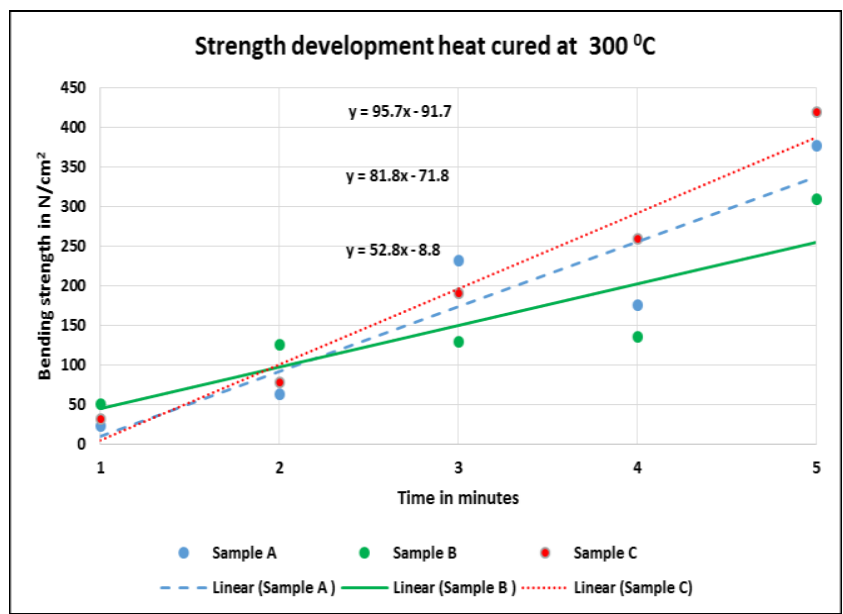

Fig. 9. Strength development heat cured system

The heat cured strength development presented in figure 9 showed a linear trend between 1-5 minutes. The increased curing time over the curing period resulted in increased strength for sample A and sample C sands. Sample B had an initially higher strength development but the rate of strength development increased at a slower rate as compared to that of sample $\mathrm{A}$ and Sample C. Sample C had an outstanding strength development for the heat cured system resulting in higher strength. The line graphs in Figure 9 are represented by equations 7, 8, and 9 .

Sample A heat cured

$y=81.80 x-71.80$

Sample B heat cured

$y=52.80 x-8.80$

Sample C carbon dioxide cured

$y=95.7 x-91.70$

The results for carbon dioxide performance with Cast clean S27 $\mathbb{R}$ at a similar module binder of 2.5 compared to the study by Stachowicz using a binder from Zakłady Chemiczne "Rudniki" are within the same range dependent on the moulding sand used the range is from $255-386 \mathrm{~N} / \mathrm{cm}^{2}$. Zakłady Chemiczne "Rudniki" results were $320 \mathrm{~N} / \mathrm{cm}^{2}$, with 120 minutes of heating time at $110^{\circ} \mathrm{C}$ [13]. The Cast clean S27 strength was achieved with 5 minutes heating time at $250^{\circ} \mathrm{C}$ as presented in figure 9 .

\subsection{Residual strength evaluation}

The residual strengths were evaluated after being subjected to the sample preparation procedure in table 2 . The prepared samples were exposed to heat ranging from $300{ }^{\circ} \mathrm{C}-1200{ }^{\circ} \mathrm{C}$. After cooling to room temperature the bending strength was determined and the results plotted on the graphs in figures 10,11 and 12 .

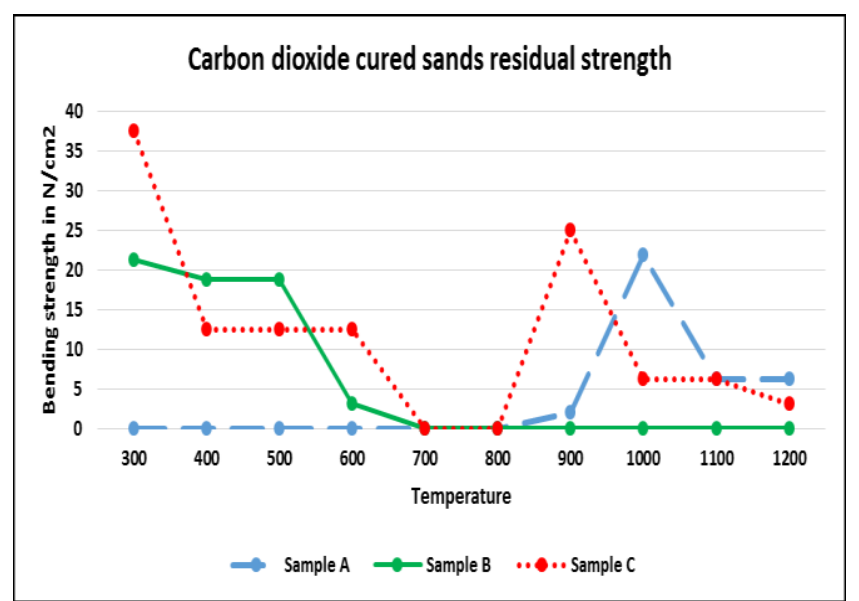

Fig. 10. Residual strength of carbon dioxide cured sands

The carbon dioxide cured sands residual strength results presented in figure 10 illustrate that sample A showed a quick drop in strength relative to sample B and C. Sample B showed an incosistency which is does not follow most literature of not having a secondary peak between $900{ }^{\circ} \mathrm{C}$ and $1000{ }^{\circ} \mathrm{C}$. Sample A and $C$ had secondary peaks of $22 \mathrm{~N} / \mathrm{cm}^{2}$ and $25 \mathrm{~N} / \mathrm{cm}^{2}$ respectively. With a futher increase in temperature by $100{ }^{\circ} \mathrm{C}$ the peaks dropped to about $6 \mathrm{~N} / \mathrm{cm}^{2}$. The sample A subrounded medium sphericity sand grains shown in the images in figure 2 are most likely the cause of good flowability and through curing with crabon dioxide. The carbon dioxide curing resulted in weaker bonds. Sample B and sample C due to inferior properties related to gas curing completed curing by heat resulting in much stronger bonds,. Therefore part of the heat resulted in curing instead of participating in breakdown. The breakdown in sample B and C was from stronger bonds thus taking more heat to breakdown relative to sample A.

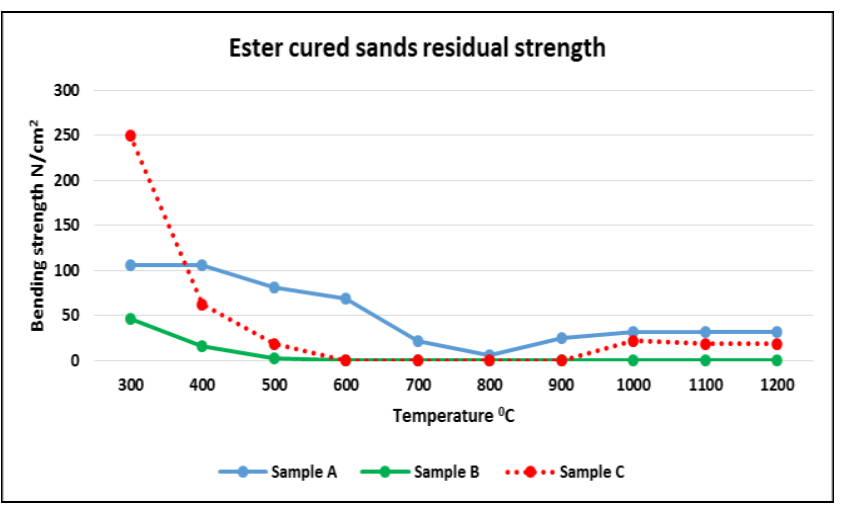

Fig. 11. Residual strength of ester cured sands

The ester cured sands residual strength results presented in figure 11 illustrate that sample A showed a slow drop in strength relative to sample B and C. The slow drop in strength could be as a result of increased rigidity. Sample B showed an incosistency which is does not follow most literature of not having a secondary peak above $900^{\circ} \mathrm{C}$. This could be as a result of high $\mathrm{Al}_{2} \mathrm{O}_{3}$ content presented in table 3 that is known to assist with breakdown 
behaviour. The $\mathrm{Al}_{2} \mathrm{O}_{3}$ gamma phase is known to appear at high temperatures. The gamma phase is known to stabilise $\alpha \mathrm{SiO}_{2}$ thereby reducing the expansion of the silica sand and at the same time improves the knockout properties of the moulding sand [11]. Sample A and C secondary peaks remained constant at $31 \mathrm{~N} / \mathrm{cm}^{2}$ and $22 \mathrm{~N} / \mathrm{cm}^{2}$ from $1000{ }^{\circ} \mathrm{C}-1200{ }^{\circ} \mathrm{C}$. This most likely due to residual products from the ester chemical bonding process.

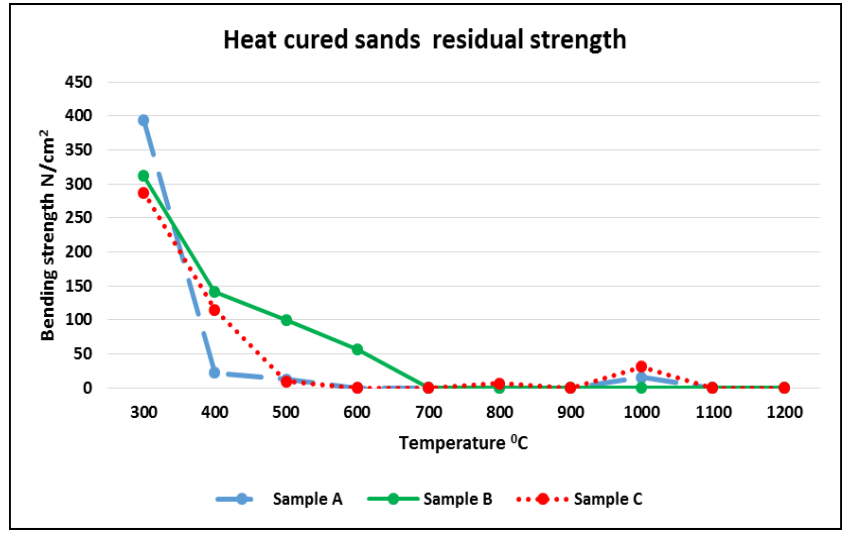

Fig. 12. Residual strength of heat cured sands

The heat cured sands residual strength results presented in figure 12 illustrate that sample B showed a slow drop in strength relative to sample A and C. Sample B showed an incosistency which does not follow most literature. Sample B does not have a secondary peak above $900^{\circ} \mathrm{C}$. This could be as a result of high $\mathrm{Al}_{2} \mathrm{O}_{3}$ content presented in table 3 that is known to assist with breakdown behaviour [11]. Sample A and C secondary peaks were at $16 \mathrm{~N} / \mathrm{cm}^{2}$ and $31 \mathrm{~N} / \mathrm{cm}^{2}$. Sample $A$ and sample $C$ strength dropped to $0 \mathrm{~N} / \mathrm{cm}^{2}$ at $1100{ }^{\circ} \mathrm{C}$. This could be as a result in stresses on the sintered material. The residual bending strength attained between $800-1200{ }^{\circ}$ Cwith Cast Clean S27 binder ${ }^{\circledR}$ are lower as compared to those presented on silicate bonded moulding sand by Foseco [15]. The results presented in the Foseco article show strengths between $20-80 \mathrm{~N} / \mathrm{cm}^{2}$ [14]. The results presented in figure 10,11 , and 12 show a range between 0 $31 \mathrm{~N} / \mathrm{cm}^{2}$. This is mainly dependent on the silica sand and curing method used. However both the upper and lower limits at the given temperatures are much lower for Cast Clean S 27 ( which is an indication that it has improved knock out properties.

\section{Conclusions}

The three different South African refractory silica sands have different physical and chemical properties. The silica sand properties influence the strength development of the single component inorganic binder at different stages of curing. Irrespective of their advantages and disadvantages in physical and chemical properties the strength development can be almost similar within certain time periods of curing. The silica sand physical and chemical properties provide different advantages over each other based upon the curing mechanism. The South African sands have different residual strength patterns.
Sample A silica sand has more benefits when using gas cured mechanisms. It is capable of reaching high strengths with less gas. The lower coefficient of angularity and low clay content promote a better movement of gas through the sand resulting in more uniform curing. The residual strength trend of sample A is more favourable with gas and heat curing.

Sample B silica sand is capable of achieving high strengths within short curing periods. This benefit is compromised with increase in curing time which results in ultimately lower final strengths. Sample B carbon dioxide cured sand completely loses strength after 24 hours. The high amount of alkali oxides and high amount of clay are detrimental to strength development. However sample $\mathrm{B}$ sand has an advantage of not having a secondary peak. This could be as a result of a higher content of $\mathrm{Al}_{2} \mathrm{O}_{3}$, which is known to improve shake out behaviour associated with the residual strength.

Sample C silica sand is capable of achieving high strengths with ester cured and heat cured systems. There is however a need to investigate the potential strength of sample $\mathrm{C}$ silica sand with reclamation taking into account that it can achieve good strengths with increased curing time despite the fact that it has a high coefficient of angularity. Sample $\mathrm{C}$ has a residual peak strength with a behaviour similar to that of sample A and seems to be slightly advantageous with ester cured systems.

Cast clean S27® inorganic foundry binder has good strength performance as long as the base silica sand has the desirable properties for the curing method. The residual bending strength trend of the binder shows variations depending on the sand or curing methods.

\section{Acknowledgements}

I would like to thank the University of Johannesburg Metal Casting Technology station and its staff for supporting the project and Peak Deutschland GmbH for providing the binder.

\section{References}

[1] Izdebska-Szanda, I., Stefaski, Z., Pezarski, F. \& Szolc, M. (2009). Effect of additives promoting the formation of lustrous carbon on the knocking out properties of foundry sands with new inorganic binders. Archives of Foundry Engineering. 9(1), 17-20.

[2] Ji-na, W., Zi-tian, F., Hua-fang, W., Xuan-pu, D. I Nai-yu, H. (2007). An improved sodium silicate binder.

[3] Izdebska-Szanda, I. \& Balisnki, A. (2011). New generation ecological silicate binders. Procedia Engineering. 10(ICM 11), 887-893.

[4] Brown, R. (2000). Foseco ferrous foundrymen handbook. Oxford: Butterworth Heinneman.

[5] Panigrahi. (1991). Selection of moulding methods and materials. W D. GL, Moulding processes and sand system (1.3-1.23). Kolkata: Indian Institute of Foundrymen.

[6] Krishnamoorthy, A. (1991). Sand control practice in ferrous foundries. Kolkata: Indian Institute of Foundrymen. 
[7] Rabii, A. (2001). Sodium Silicate Glass as an Inorganic Binder in Foundry Industry. Iranian polymer journal. 10, 229-235.

[8] Polzin, H. (2014). Inorganic binders for mould and core production in the foundry. Berlin: Schiele and Schon Gmbh.

[9] Lochte, K. (1998). Working with the cold box process in the coremaking department of the foundry. Hüttenes-Albertus Chemische Werke GmbH. tom July 1998.

[10] Hoyt, D.F. (2007). Identifying and eliminating the variables that affect no bake and cold box binder systems. American Foundry Society (AFS) transactions Paper 7-001, pp. 1-20.

[11] Owusu, Y.A. (1982). Physical and chemical study of sodium silicate as a foundry sand binder. Advances in colloid and interface science, pp. 57-91.

[12] Dobosz, S., Jelinek, P. \& Major-Gabrys, K. (2011). Development tendencies of moulding and core sands. China Foundry.
[13] Granat, K., Nowak, D., Pigiel, M., Stachowicz, M. \& Wikiera, R. (2009). Determination of application possibilities of microwave heating in the curing process of water glass molding sands with fluid esters Part 1. Archives of Foundry Engineering. 9(1), 45-50.

[14] Stachowicz, M., Granat, K., Nowak D., \& Haimann, K. (2010). Effect of hardening methods of moulding sands with water glass on structure of bonding bridges. Archives of Foundry Engineering. 10(3), 123-128.

[15] Foseco, "https://www.scribd.com/document/88700185/24201-Silicate-Bonded-Moulding-Sand\#," [Online]. Available: https://www.scribd.com/document/88700185/242-01Silicate-Bonded-Moulding-Sand\#. [Accessed 2202 2017]. 